\title{
Assessment of fluid responsiveness with end-tidal carbon dioxide using a simplified passive leg-raising maneuver: a prospective observational study
}

\author{
Michal Barak, MD • Eliot Yussim, MD
}

Received: 7 December 2016/Revised: 27 December 2016/ Accepted: 13 February 2017/Published online: 23 February 2017

(C) Canadian Anesthesiologists' Society 2017

\section{To the Editor,}

We read with great interest the study published by Dr. Toupin et al. regarding the assessment of fluid responsiveness with end-tidal carbon dioxide using a simplified passive leg-raising maneuver. ${ }^{1}$ The authors demonstrated the physiological response to volume using this simple model and attributed the change in end-tidal $\mathrm{CO}_{2}\left(\mathrm{ETCO}_{2}\right)$ to increased cardiac output. However, we suggest another explanation for the increased $\mathrm{ETCO}_{2}$ that follows the passive leg-raising maneuver. When the patient undergoes positive-pressure ventilation, the alveolar dead space, also called "West zone 1", is increased., When the passive leg-raising maneuver is performed, the blood flow to the lungs is increased owing to gravity, thereby increasing alveolar perfusion. That sequence decreases the alveolar dead space (i.e., "West zone 1") and increases "West zone 2". Thus, the $\mathrm{ETCO}_{2}$ is increased. This phenomenon does not necessarily imply a change in cardiac output.

Indeed, positive-pressure ventilation causes a greater increase in alveolar dead space in the hypovolemic patient than in the normovolemic patient. Thus, the hypovolemic patient's lung perfusion responds to a greater extent to leg-raising or fluid administration, and the change in $\mathrm{ETCO}_{2}$ is more prominent. These results imply that patients who are "responders" respond to volume administration in both the cardiovascular and pulmonary systems. It is important to remember that the $\mathrm{ETCO}_{2}$ represents a combination of cardiac, thoracic, pulmonary, vascular, and intravascular volumes, and alteration in any one of them may change the $\mathrm{ETCO}_{2}$.

Conflicts of interest None declared.

Editorial responsibility This submission was handled by Dr. Philip M. Jones, Associate Editor, Canadian Journal of Anesthesia.

\section{References}

1. Toupin F, Clairoux A, Deschamps A, et al. Assessment of fluid responsiveness with end-tidal carbon dioxide using a simplified passive leg raising maneuver: a prospective observational study. Can J Anesth 2016. DOI:10.1007/s12630-016-0677-z.

2. Siobal MS. Monitoring exhaled carbon dioxide. Respir Care 2016. DOI:10.4187/respcare.04919.

3. Robertson HT. Dead space: the physiology of wasted ventilation. Eur Respir J 2015. DOI:10.1183/09031936.00137614.

This letter is accompanied by a reply. Please see Can J Anesth 2017; 64: this issue.

M. Barak, MD $(\bowtie) \cdot$ E. Yussim, MD

Department of Anesthesia, Rambam Health Care Campus, Haifa,

Israel

e-mail: m_barak@rambam.health.gov.il

M. Barak, MD

The Ruth and Bruce Rappaport Faculty of Medicine,

Technion-Israel Institute of Technology, Haifa, Israel 